\title{
Loss of Food Nutrients orchestrated by Cooking Pots: a common trend in developing world
}

\author{
Uloma Onyeka and Obinna Ibeawchi \\ Federal University of Technology, Owerri, Nigeria
}

\begin{abstract}
There is abundant evidence that cooking reduces the level of nutrients in foods, but the reductions are exacerbated by among other factors the type of cooking pot used. We conducted a research to determine the influence of various cooking pots on macro and micronutrients of cooked foods. Seven pots and five types of food stuffs were used for the study. The cooking pots used included unpitted aluminum, pitted aluminum, stainless steel, titanium, enamel coated, clay (earthen) and iron-cast while the food stuff were chosen from the major classes of food as to include tubers (yam), cereals (rice), fleshy (beef), vegetables (tomato) and legumes (cowpea). Cooking pot forged from titanium offered best (up to $87.7 \%$ ) protection (retention) of micronutrients while pitted aluminum pot offered the least retention irrespective of the food sample cooked. Significant portions of food micro nutrients namely vitamin $\mathrm{C}$, vitamin A and selenium were mostly affected compared with the macro nutrients. In the course of our investigations we observed that titanium and enamel coated cooking pots required less quantity of water to get food done. The use of less water to cook transmitted to low $(69.67 \%)$ moisture content of food cooked in such pots compared to values as high as $76.89 \%$ when other pots were used. Food cooked with less water may impact better taste to food since the food is expected to be more nutrient-dense; having considerable lower moisture content. Our research evidenced that cooking pot can have a strong impact on people's morbidity since some pots can aggravate hidden hunger, that is, micronutrient malnutrition. Hidden hunger is a subtle enemy that drains away health and vitality unnoticed until it is too late to reverse. It is crucial to state here that our findings may have turned on its head the previous idea of using pressure pot to cook food. Pots that offered low-pressure cooking $\left(80^{\circ} \mathrm{C} / 0.48\right.$ bar $)$ was found to preserve the most heat liable (vitamin $\mathrm{C}$ and volatiles) nutrients probably because of the lower water boiling temperature and reduced level of oxygen. Our conclusion and recommendation, therefore, is the use of titanium and enamel surface coated cooking pots which offered better protection of food micronutrients among other cooking pots tested. This is a piece of information that is quite vital and beneficial to food consumers, manufacturers of cook wares, operators and key players in the food processing industry.
\end{abstract}

\section{Conflict of Interest}

There is no conflict of interest. 